\title{
The Orbital and Medial Prefrontal Circuit Through the Primate Basal Ganglia
}

\author{
S. N. Haber, ${ }^{1}$ K. Kunishio, ${ }^{2}$ M. Mizobuchi, ${ }^{2}$ and E. Lynd-Balta' \\ ${ }^{1}$ Department of Neurobiology and Anatomy, University of Rochester School of Medicine, Rochester, New York \\ 14642 and ${ }^{2}$ Department of Neurological Surgery, University of Okayama Medical School, Okayama 700, Japan
}

The ventral striatum is considered an interface between limbic and motor systems. We followed the orbital and medial prefrontal circuit through the monkey basal ganglia by analyzing the projection from this cortical area to the ventral striatum and the representation of orbitofrontal cortex via the striatum, in the globus pallidus and substantia nigra. Following injections of Lucifer yellow and horse radish peroxidase into the medial ventral striatum, there is a very densely labeled distribution of cells in areas $13 a$ and $13 b$, primarlly In layers $V$ and VI, and in medial prefrontal areas 32 and 25 . Injections into the shell of the nucleus accumbens labeled primarily areas 25 and 32 . The reaction product in the globus pallidus and the substantia nigra supports previous studies demonstrating that efferent projections from the ventral striatum are represented topographically in the ventral pallidum and nontopographically in the substantia nigra, pars compacta. Tritiated amino acid or PHA-L tracer injections into orbitofrontal cortex produce dense patches of terminal labeling along the medial edge of the caudate nucleus and the dorsal part of the nucleus accumbens.

These results demonstrate that the orbital prefrontal cortex projects primarily to the medial edge of the ventral striatum and to the core of the nucleus accumbens. The arrangement of terminals in the globus pallidus and substantia nigra show two different patterns. Thus, the orbital and medial prefrontal cortex is represented in a confined region of the globus pallidus but throughout an extensive area of the dorsal substantia nigra. Terminals are extensive throughout the region of the dopaminergic neurons, suggesting that this input may influence a wide area of both the striatum and frontal cortex.

[Key words: limbic system, shell region of the nucleus accumbens, ventral striatum, substantia nigra, ventral pallidum, orbital and medial prefrontal cortex]

\footnotetext{
Received Aug. 5, 1994; revised Jan. 25, 1995; accepted Jan. 31, 1995.

We gratefully acknowledge the gift of Lucifer yellow antisera from Dr. $\mathrm{H}$. Chang. We thank Dr. Scott Zahm for reading the manuscript and his thoughtful comments on the shell and core compartments of the nucleus accumbens. We also thank Dr. Joel Price for reading the manuscript and discussions concerning the regions of orbital and medial prefrontal cortex. This work was supported by NIH Grant NS 22511 , NIMH Grant MH 45573, and a grant from the Lucille P. Markey Charitable trust award.

Correspondence should be addressed to Suzanne N. Haber, Department of Neurobiology and Anatomy, University of Rochester, 601 Elmwood Avenue, Rochester, NY 14642.
}

Copyright (C) 1995 Society for Neuroscience $0270-6474 / 95 / 154851-17 \$ 05.00 / 0$
The ventral striatum has long been considered an interface between the limbic cortex and motor response to stimuli (Nauta and Domesick, 1978; Mogenson et al., 1980). Physiological, pharmacological, and behavioral studies have demonstrated the integral role the ventral striatum plays in motivated behavior (Jones and Leavitt, 1974; Mogenson et al., 1980, 1993; Mogenson and Nielsen, 1983; Apicella et al., 1991; Schultz et al., 1992; Napier et al., 1993; Koob et al., 1994). However, the anatomical framework through which the ventral striatum can influence subsequent motor output has not been worked out in the primate. One current theory concerning the organization of basal ganglia pathways proposes that the frontal cortex and the basal ganglia are arranged in parallel, functionally segregated circuits (Alexander et al., 1990). Individual circuits originate in distinct regions of the frontal cortex, and project to distinct and segregated sectors of the striatum, pallidum, thalamus, and back to the cortical region of origin. Furthermore, within each general circuit there are subcircuits which also remain segregated. Several rodent studies have demonstrated the role of the ventral striatum and ventral pallidum in the regulation of locomotor behavior through pallidal projections via the thalamic loop to frontal cortex, or directly to the brainstem locomotor areas (Mogenson and Nielsen, 1983; Swerdlow and Koob, 1984; Austin and Kalivas, 1991; Henriksen and Giachino, 1993; Mogenson et al., 1993).

Other studies suggest that some integration of cortical information takes place through the basal ganglia (Percheron et al., 1984; Kemel et al., 1992; Schultz, 1992; Schultz et al., 1993; Flaherty and Graybiel, 1994; Lynd-Balta and Haber, 1994a). In particular, rat and primate studies support the idea that the ventral striatum may modulate a wide area of the striatum via the dopaminergic neurons (Nauta et al., 1978; Somogyi et al., 1981; Haber et al., 1990; Zahm and Heimer, 1993). Indeed, an important way in which the ventral striatum can regulate motor outcome is through its direct innervation of the pars compacta dopamine neurons (Nauta et al., 1978; Somogyi et al., 1981; I Iaber et al., 1990; Heimer et al., 1991b; Zahm and Heimer, 1993; Lynd-Balta and Haber, 1994a).

The monkey striatum can be divided into different functional domains based on topographic projections from different cortical regions (Fig. 1) (Haber et al., 1992). The ventral striatum, composed of the nucleus accumbens and adjacent ventromedial caudate nucleus and ventral putamen, receives input from structures associated with the limbic system. The nucleus accumbens has been further divided into core and shell subregions in rats (Zaborszky et al., 1985; Heimer et al., 1991b; Zahm and Brog, 1992). The shell occupies the medial and ven- 


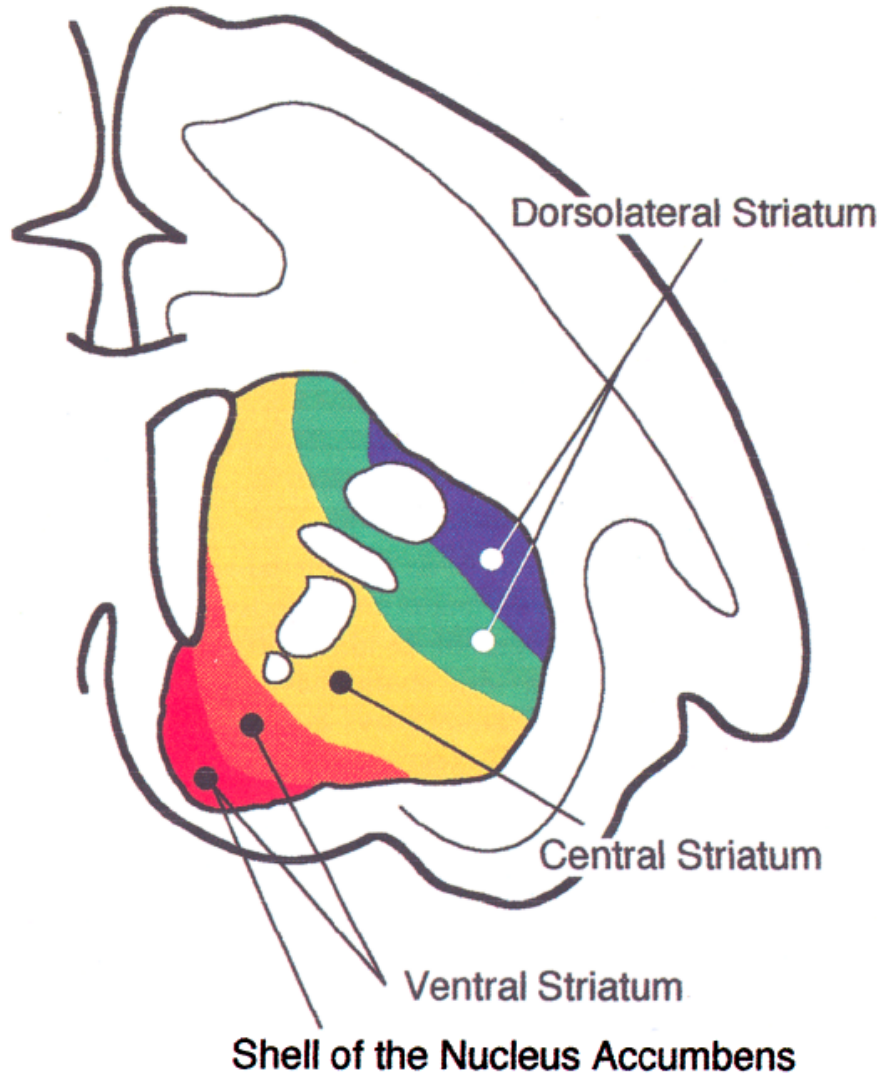

Figure 1. Schematic illustration of the topographic organization of cortical inputs that create general ventral (limbic), central (association), and dorsolateral (motor) territories of the striatum. The ventral striatum is divided into the shell of the nucleus accumbens and the other ventral striatal regions based on the calbindin- $\mathrm{D}_{28 \mathrm{k}}$ immunostaining. Red, shell of the nucleus accumbens; yellow, central (association) striatum; blue, dorsolateral (sensorimotor) striatum; orange and green, areas of overlap.

tral edge of the nucleus accumbens, has unique anatomical characteristics, and is most closely associated with the limbic system and the extended amygdala (Alheid and Heimer, 1988; Heimer et al., 1991a). In monkeys, a calbindin- $D_{28 k}$ negative region in the ventral and medial part of the ventral striatum is considered to be, in part, homologous to the shell region in the rat (Friedman et al., 1992; Meredith et al., 1993; Lynd-Balta and Haber, 1994c). The core is continuous with the surrounding ventral striatum.

In contrast to the sensorimotor pathways, little is known about the pathways of limbic cortex through the monkey basal ganglia. The orbital and medial prefrontal cortex (OMPFC) (Carmichael and Price, 1994) represents one of the largest cortical regions associated with the limbic system. We followed

Figure 2. A, Photomicrograph of calbindin- $\mathrm{D}_{28 \mathrm{k}}$ (Cabp) staining pattern in the striatum. Arrowheads denote the shell region of the nucleus accumbens which is characterized by low Cabp immunoreactivity. Abbreviations: $C a$, caudate nucleus; $P u$, putamen. $B$, Schematic drawing of the injections sites of retrograde tracers in different regions of the ventral striatum. $C$, Photomicrograph of a HRP-WGA injection site in the medial ventral striatum, case MS14. D. Photomicrograph of a HRP-WGA injection site in the shell of the nucleus accumbens, case MS35.
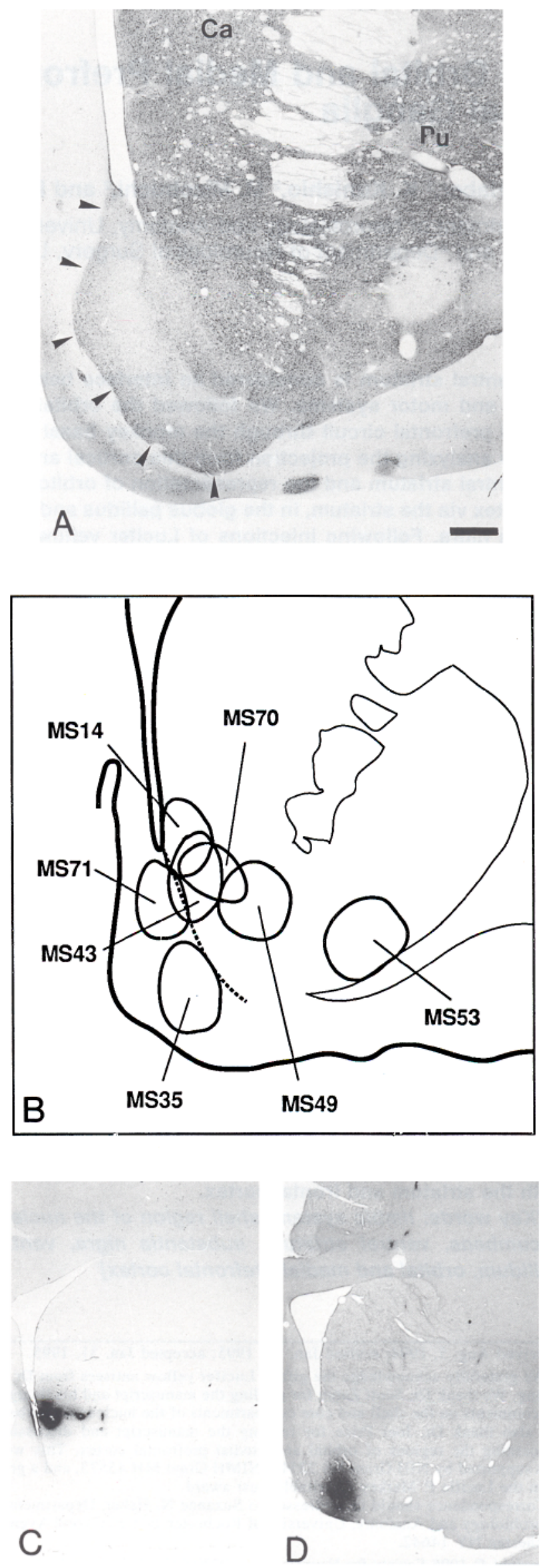

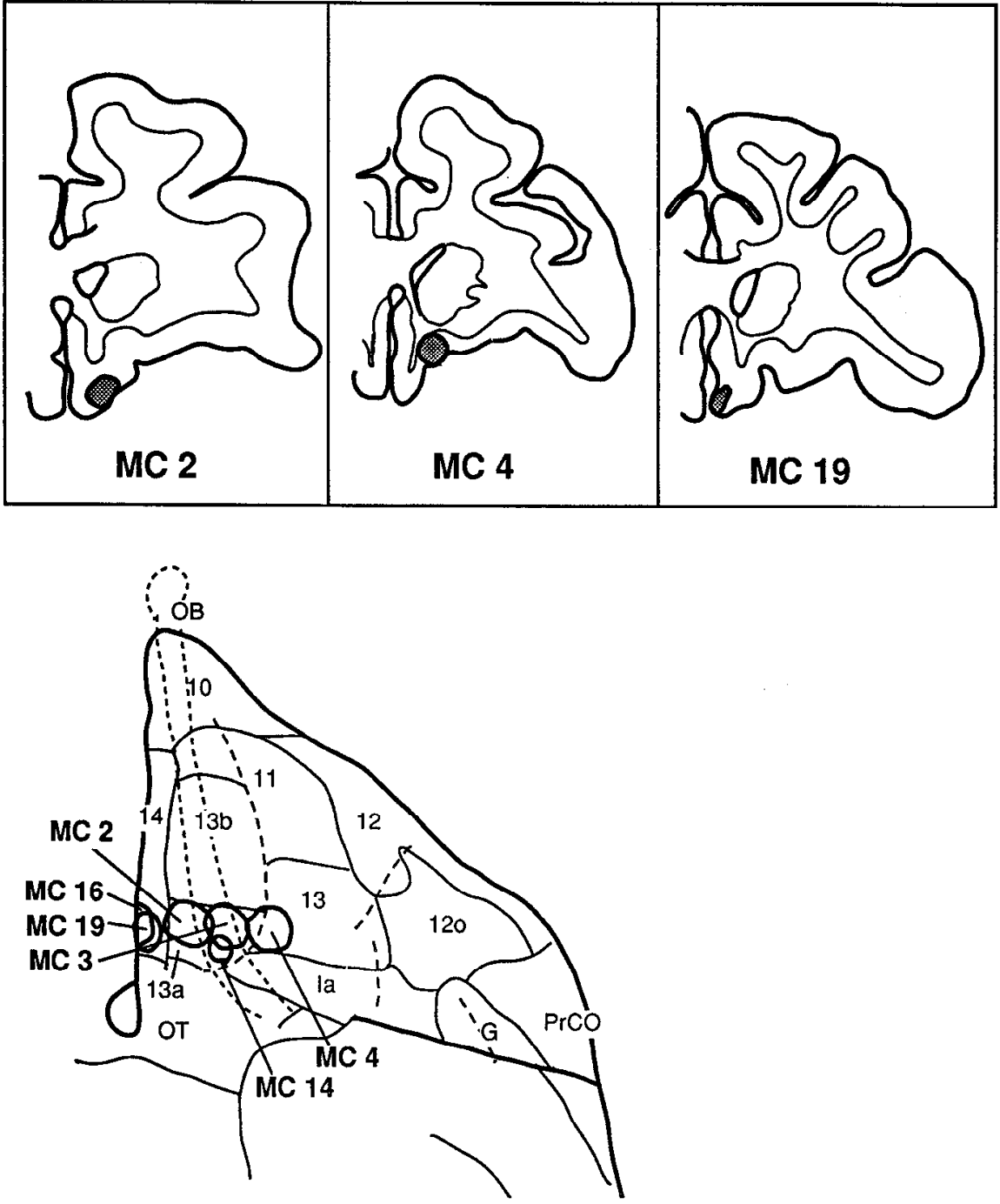

the OMPFC circuit through the basal ganglia by analyzing its projections to the various regions of the ventral striatum. To determine the extent to which this organization of frontostriatal pathways is maintained in projections from the striatum, we examined the projections from the OMPFC terminal regions in the ventral striatum to the globus pallidus and substantia nigra. We also compared these projections to those of the dorsolateral striatum.

\section{Materials and Methods}

\section{Experimental design}

The ventral striatum is defined here as the striatal region that receives a dense input from the amygdaloid complex, the hippocampus, the anterior cingulate cortex (areas 25,24a and b), the dorsal tier of the midbrain dopamine neurons including cells of the ventral tegmental area, and the midline thalamic nuclear groups (Poletti and Cresswell, 1977; Russchen et al., 1985; Kunishio and Haber, 1994; Lynd-Balta and Haber, 1994c; Giménez-Amaya et al., 1995). This area includes the nucleus accumbens, and the adjacent ventromedial caudate nucleus and ventral putamen. We have further identified the shell region of the nucleus accumbens based on calbindin- $\mathrm{D}_{28 \mathrm{k}}$ (Cabp) immunohistochemical distribution. Within the ventral striatum, there is a central region of dense Cabp-positive staining and a surrounding ventromedial region with relatively weak staining. The weakly stained Cabppositive area extends from the medial part of the nucleus accumbens into the ventral putamen (Fig. 2A). The ventral and medial Cabp-poor
Figure 3. A summary of the injection sites of anterograde tracers in distinct regions of the OMPFC. Coronal (upper) and ventral (lower) view. Abbreviations: $I a$, agranular insula cortex; $G$, gustatory cortex; $O B$, olfactory bulb; $O T$, olfactory tubercle; $\operatorname{PrCo}$ precentral opercular cortex. region is considered to correspond to the shell region in rats, while the Cabp-positive region corresponds to the core and extends into the caudate nucleus and putamen (Friedman et al., 1992; Meredith et al., 1993; Zahm and Heimer, 1993). To evaluate the topography of the OMPFC projection, injections of retrograde tracers were made into several regions of the ventral striatum. These include: the shell of the nucleus accumbens, the central region of the ventral striatum including the core of the nucleus accumbens, the medial ventral striatum (medial ventral caudate nucleus), and the lateral ventral striatum (medial ventral putamen).

The orbitofrontal cortex is made up of several cytoarchitectonic regions that represent gradual changes in laminar characteristics from a less differentiated cortex (agranular cortex) to one with clearly demarcated layers (Amaral and Price, 1984; Barbas and Pandya, 1989; Ray and Price, 1993). It includes areas 11, 12, 13, and 14 (Walker, 1940; Barbas and Pandya, 1989). These areas have been further divided into subregions (Amaral and Price, 1984; Ray and Price, 1993; Carmichael and Price, 1994). In our material, the approximate borders of these areas are based on Nissl stains and their rostrocaudal positions. In addition, we include here medial areas 32 and 25. Together we refer to this region as the orbital and medial prefrontal cortex as defined by Carmichael and Price (1994).

\section{Injection sites}

$O M P F C$ projections. Nine injections of horseradish-peroxidase conjugated to wheat germ agglutinin (HRP-WGA) and Lucifer yellow (LY) were made confined to specific regions of the striatum. The injection sites in the ventral striatum included: the medial ventral stria- 

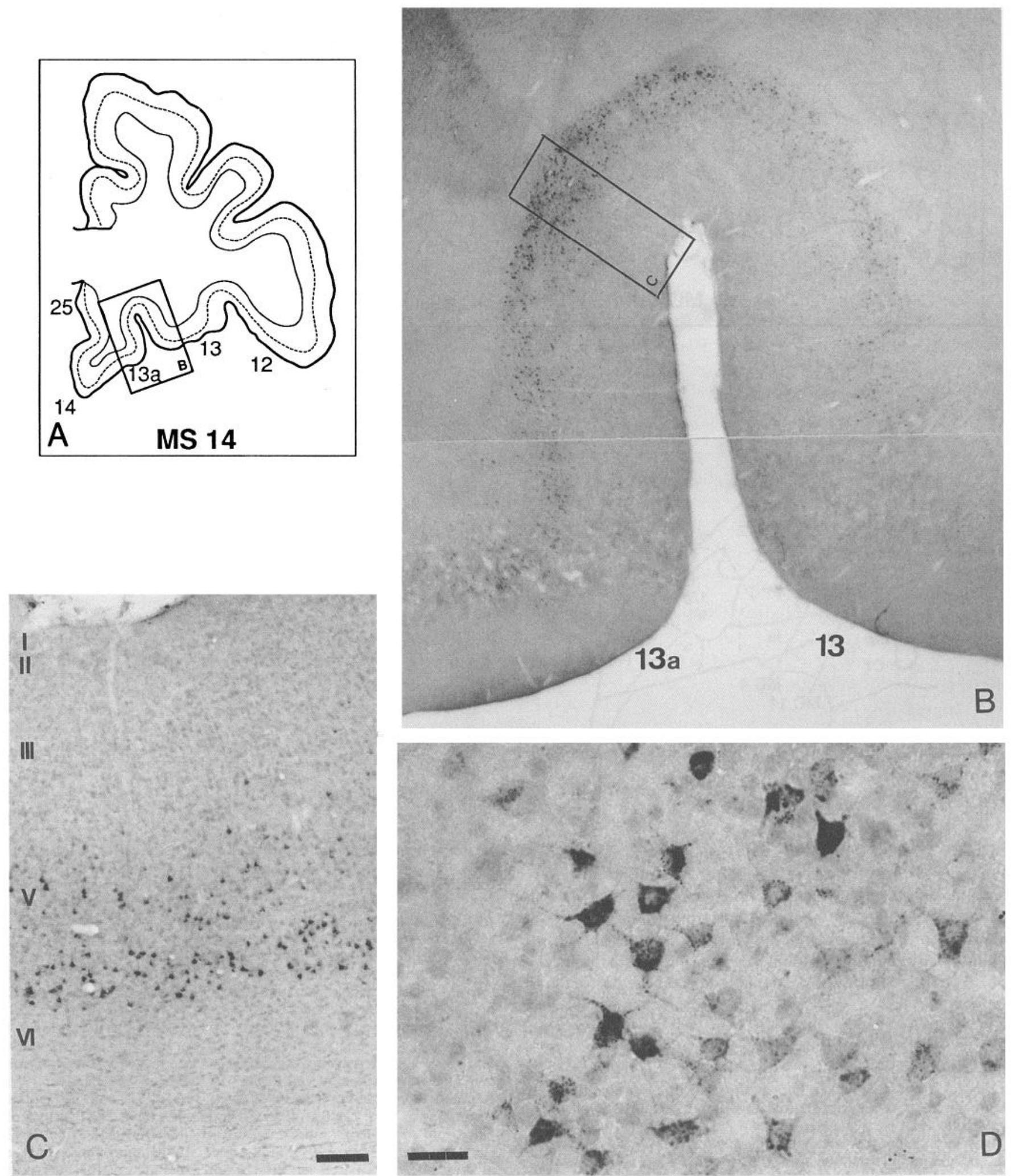

Figure 4. Photomicrographs taken from case MS14. A, Schematic illustration of OMPFC. Black rectangle marked $B$ in panel $A$ is shown in panel $B$. B. Low power photomicrograph of retrogradely labeled neurons in the orbitofrontal cortex, area 13 and $13 \mathrm{a}$. Black rectangle marked $C$ in panel $B$ is magnified in panel $C$. $C$, Labeled cells are located primarily in layer V and VI. $D$, Most cells are densely labeled while others are lightly stained. Scale bars: $B, 1 \mathrm{~mm} ; C, 20 \mu \mathrm{m} ; D, 50 \mu \mathrm{m}$. 


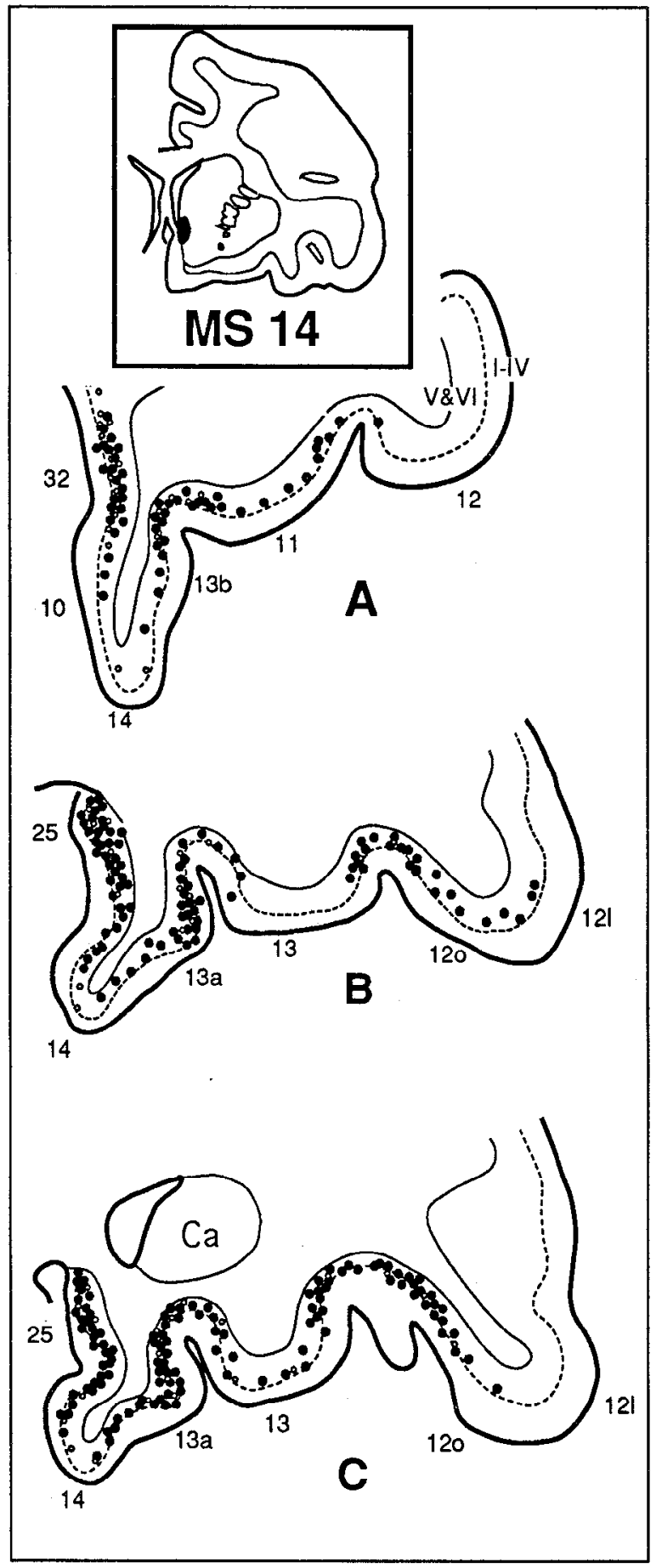

Figure 5. Distribution of retrogradely labeled neurons in the OMPFC following an injection into the medial ventral striatum, case MS14: solid circle, group of three densely labeled cells; open circle, three lightly labeled cells. Note the dense distribution of cells particularly in areas $32,13 \mathrm{~b}, 25$, and $13 \mathrm{a}$. $\mathrm{Ca}$, caudate nucleus.

tum; the lateral ventral striatum; the central ventral striatum, including the core of the nucleus accumbens (all Cabp-positive regions); and the shell of the nucleus accumbens (Cabp-negative region) (Fig. 2). To examine the topographic specificity of projections to the ventral striatum, some tracer injections were also placed in the dorsal sensorimotor regions of the striatum.

Experiments MS14, MS43, and MS70 have HRP-WGA injection sites centered in the medial portion of the ventral striatum within a

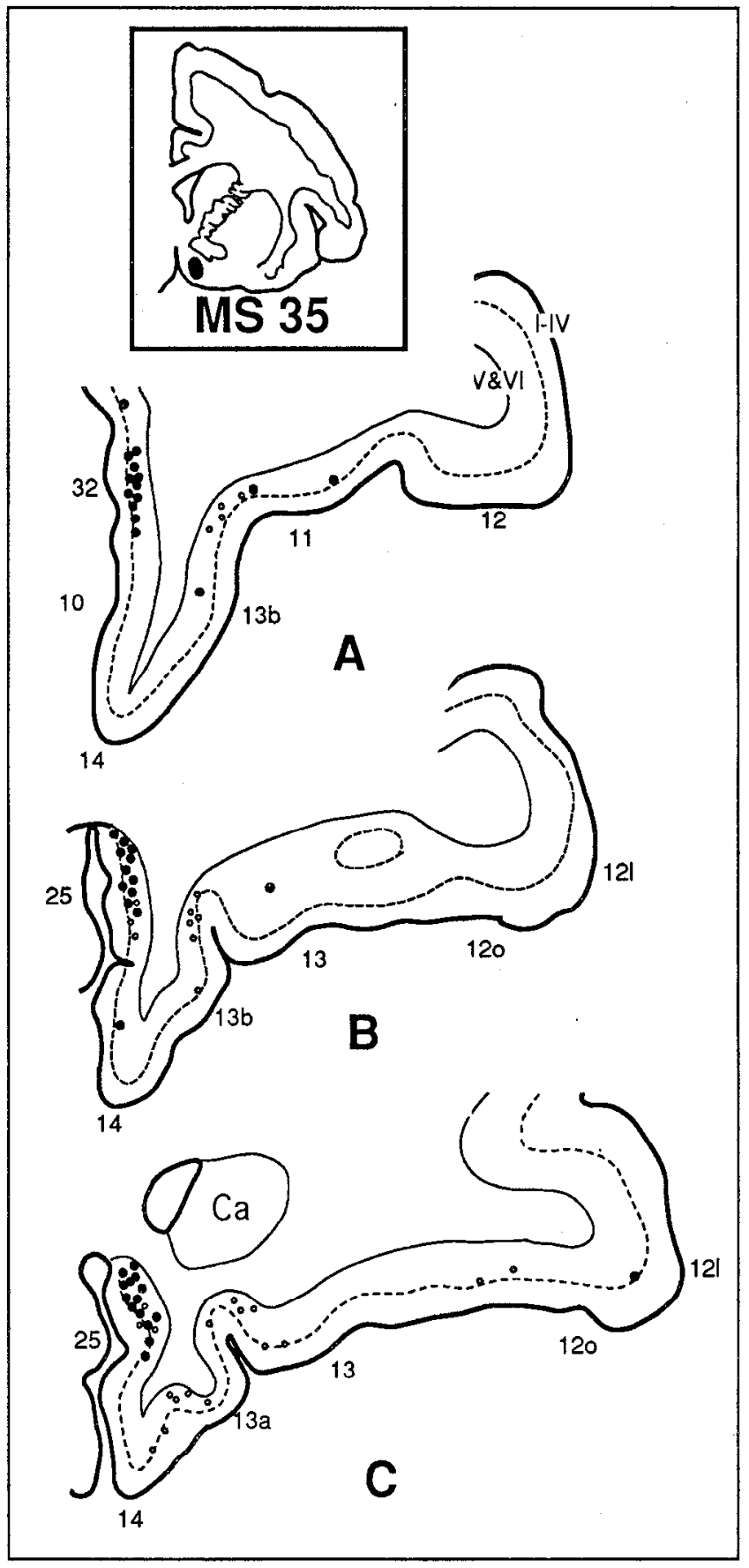

Figure 6. Charting of the distribution of retrogradely labeled neurons following an injection into the shell of the nucleus accumbens, case MS35: solid circle, group of three densely labeled cells; open circle, group of three lightly labeled cells. Note the concentration of labeled cells in medial areas 32 and 25. $\mathrm{Ca}$, caudate nucleus.

Cabp-positive region. MS20 (not illustrated) is also a medial injection but is placed very rostrally in the caudate nucleus. MS53 is an injection of LY into the lateral ventral striatum. Although much of the putamen is innervated by sensorimotor-related cortices, this rostral, ventral area of the putamen receives inputs from the amygdala, the dorsal tier and densocellular zone of midbrain dopaminergic neurons and the anterior cingulate cortex (Russchen et al., 1985; Kunishio and Haber, 1994; Lynd-Balta and Haber, 1994c). This region does not receive sensorimotor input (Lynd-Balta and Haber, 1994b). Experiment MS49 is an injection into the central ventral striatum including 


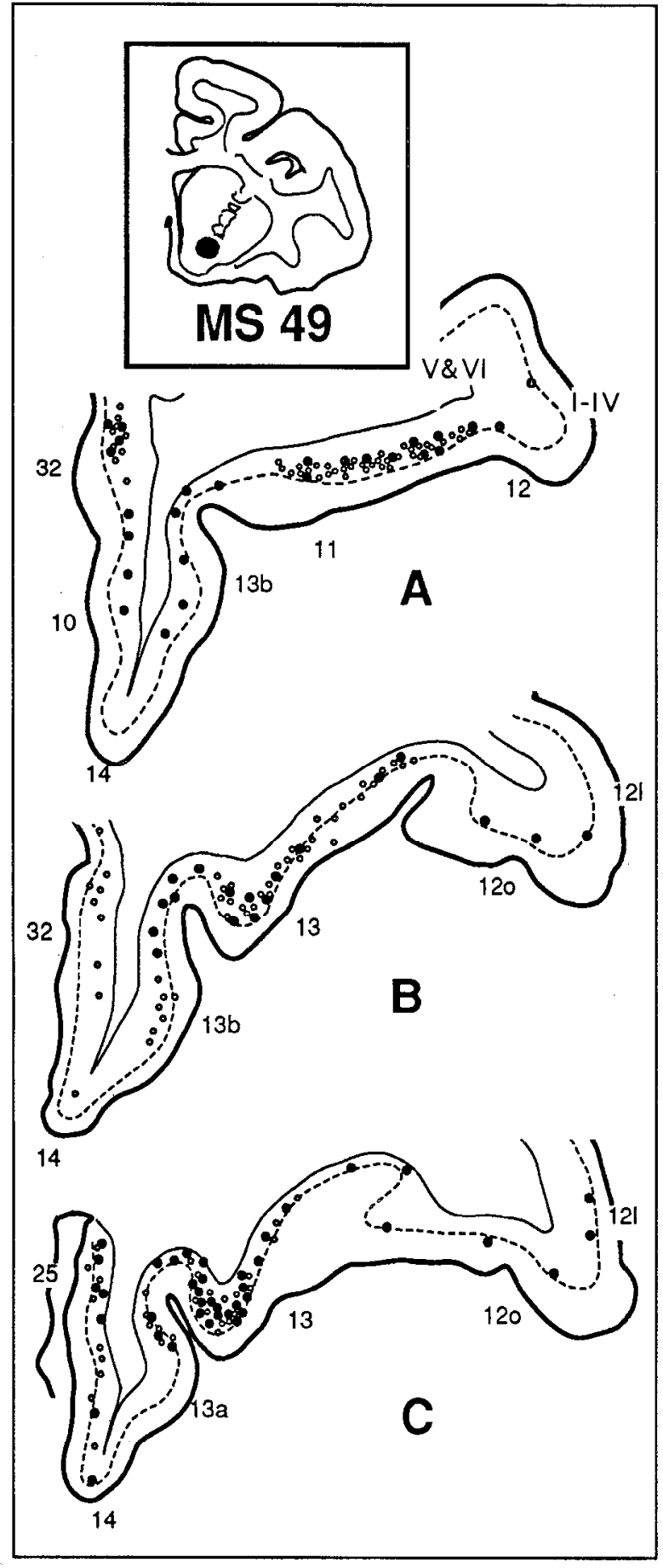

Figure 7. Distribution of retrogradely labeled neurons in the OMPFC following an injection into the central region of the ventral striatum including the core of the nucleus accumbens, case MS49: solid circle, groups of three densely labeled cells; open circle, three lightly labeled cells. Densely labeled cells are particularly concentrated in areas 11 and 13 .

the core of the nucleus accumbens, part of the ventrolateral caudate nucleus, and ventromedial putamen. Finally, experiments MS35 and MS71 are HRP-WGA injection sites confined, respectively, to the ventral and medial shell region of the nucleus accumbens, as determined by Cabp-staining patterns. This region receives a specific input from the dorsal, but not from the ventral tier neurons of the substantia nigra (Lynd-Balta and Haber, 1994c). In five additional cases, retrograde

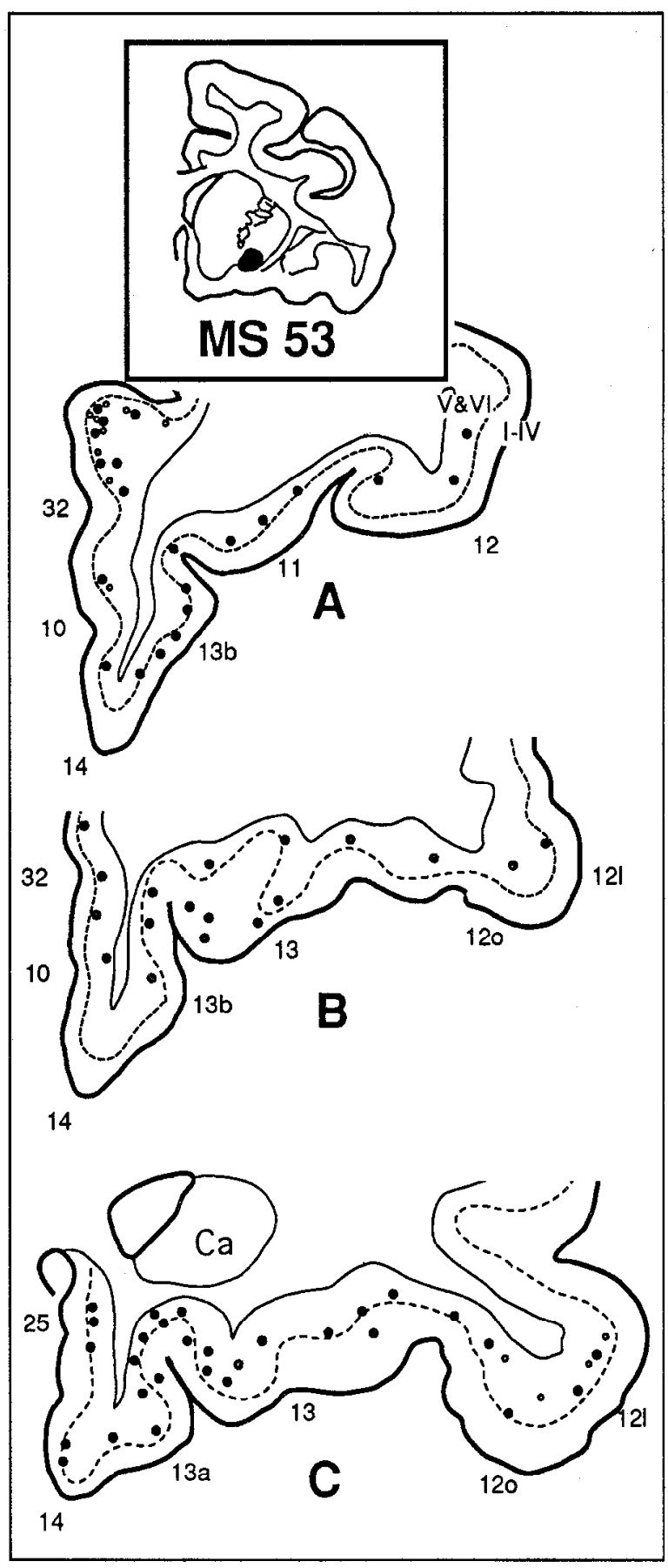

Figure 8. Distribution of retrogradely labeled neurons in the OMPFC following an injection into the lateral ventral striatum, case MS53: solid circle, group of three densely labeled cells; open circle, group of three lightly labeled cells. $\mathrm{Ca}$, caudate nucleus.

tracers were also injected into striatal regions innervated by the sensorimotor cortex. For comparison, case MS56 (see Fig. 10) is illustrated as an injection site centered in a dorsal striatal region that receives input from the sensorimotor cortex.

To verify our results in cortex obtained from the LY and WGA HRP experiments we also made several injections of anterograde tracers into cortical areas 13 and 14 (Fig. 3). Three cases are described in detail. MC2 is a tritiated amino acids injection centered in area 13a, MC4 is an injection of tritiated amino acids primarily centered in area 13 , and MC19 (LY) is centered in area 14. 


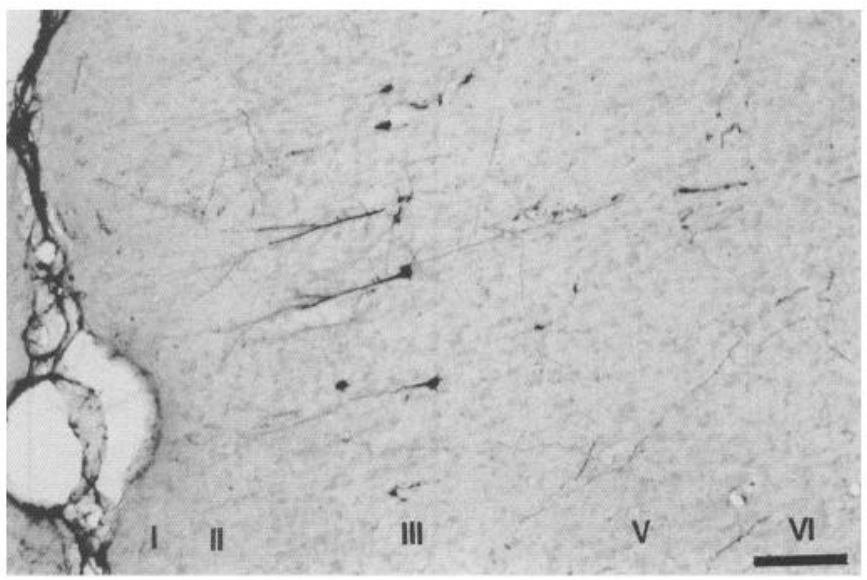

Figure 9. Photomicrograph taken from case MS53. The Golgi-like densely labeled cells are scattered primarily in layer III. Scale bar, 300 $\mu \mathrm{m}$.

The organization of OMPFC projections through the basal ganglia were followed to the globus pallidus and substantia nigra by examining the LY and WGA-HRP reaction product in the globus pallidus and substantia nigra. These results were compared to previously published data using PHA-L and tritiated amino acid injections in the same regions of the ventral striatum.

\section{Experimental procedures}

Thirteen adult old world monkeys (8 Macaca mulatta and $14 \mathrm{Ma}$ caca nemestrina) were used for these experiments. Following initial anesthesia with an intramuscular injection of ketamine $(10 \mathrm{mg} / \mathrm{kg})$, a deep surgical level of anesthesia was maintained with pentobarbital (initial dose $20 \mathrm{mg} / \mathrm{kg}$ i.v., and maintained as needed). Electrophysiological mapping was performed to locate appropriate injection sites. Serial electrode penetrations (glass-insulated etched platinumiridium electrodes) were made throughout the rostrocaudal and mediolateral extent of the striatum to identify neuronal activity based on patterns of electrophysiological recordings (Haber et al., 1993). The location of neurons encountered in a series of penetrations was used to prepare a map indicating the boundaries of different basal ganglia structures. The absence of cellular activity was noted in the area of fiber tracts, that is, the corpus callosum, the internal capsule, and the anterior commissure. Accurate placement of the tracers was subsequently achieved by careful alignment of the injection cannulae with the electrode. Anterograde tracers included tritiated amino acids (tritiated leucine and tritiated proline), $50-80 \mathrm{mCi}$, in $200 \mathrm{nl}$ saline, Phaseolus vulgaris-leucoagglutinin (PHA-L), $80 \mathrm{nl}$ of $2.5 \%$ in $0.05 \mathrm{M}$ Tris buffer (Vector Laboratories, Burlingame, CA), and LY (20-40 nl of $10 \%$ in $\mathrm{dH}_{2} \mathrm{O}$, Molecular Probes, Eugene, OR). Retrograde tracers included HRP-WGA (40-50 nl, 4\%, Sigma), and LY. All tracers were pressure-injected into discrete regions of the striatum or into the orbitofrontal cortex. Following an injection, the syringe remained in situ for 20-30 min to prevent leakage up the needle track. The protocol for LY as a tracer has been modified for use in primates (Lynd-Balta and Haber, 1994c). Nine to $14 \mathrm{~d}$ after surgery, the animals were again deeply anesthetized and perfused through the heart with saline followed by a $4 \%$ paraformaldehyde solution in $0.1 \mathrm{M}$ phosphate buffer, $\mathrm{pH} 7.4$. The brains were cryoprotected in increasing gradients of sucrose $(10 \%, 20 \%$, and finally $30 \%$ ). Serial sections of $50 \mu \mathrm{m}$ were cut on a freezing microtome and processed for autoradiography or immunocytochemistry (ICC) for HRP-WGA, PHA-L, or LY.

Sections for autoradiography were mounted on chrome-alum gelatin coated slides and defatted in xylene overnight. Slides were dipped in Kodak NTB2 photographic emulsion and exposed for 6-12 weeks at $4^{\circ} \mathrm{C}$ in a light-tight box. The sections were then developed in Kodak D19 for $2.5 \mathrm{~min}$, fixed, washed, and counterstained with cresyl violet.

Sections to be immunoreacted with anti PHA-L, anti-LY, or antiHRP-WGA were first rinsed in $0.1 \mathrm{M}$ phosphate buffer ( $\mathrm{pH} 7.4$ ) with

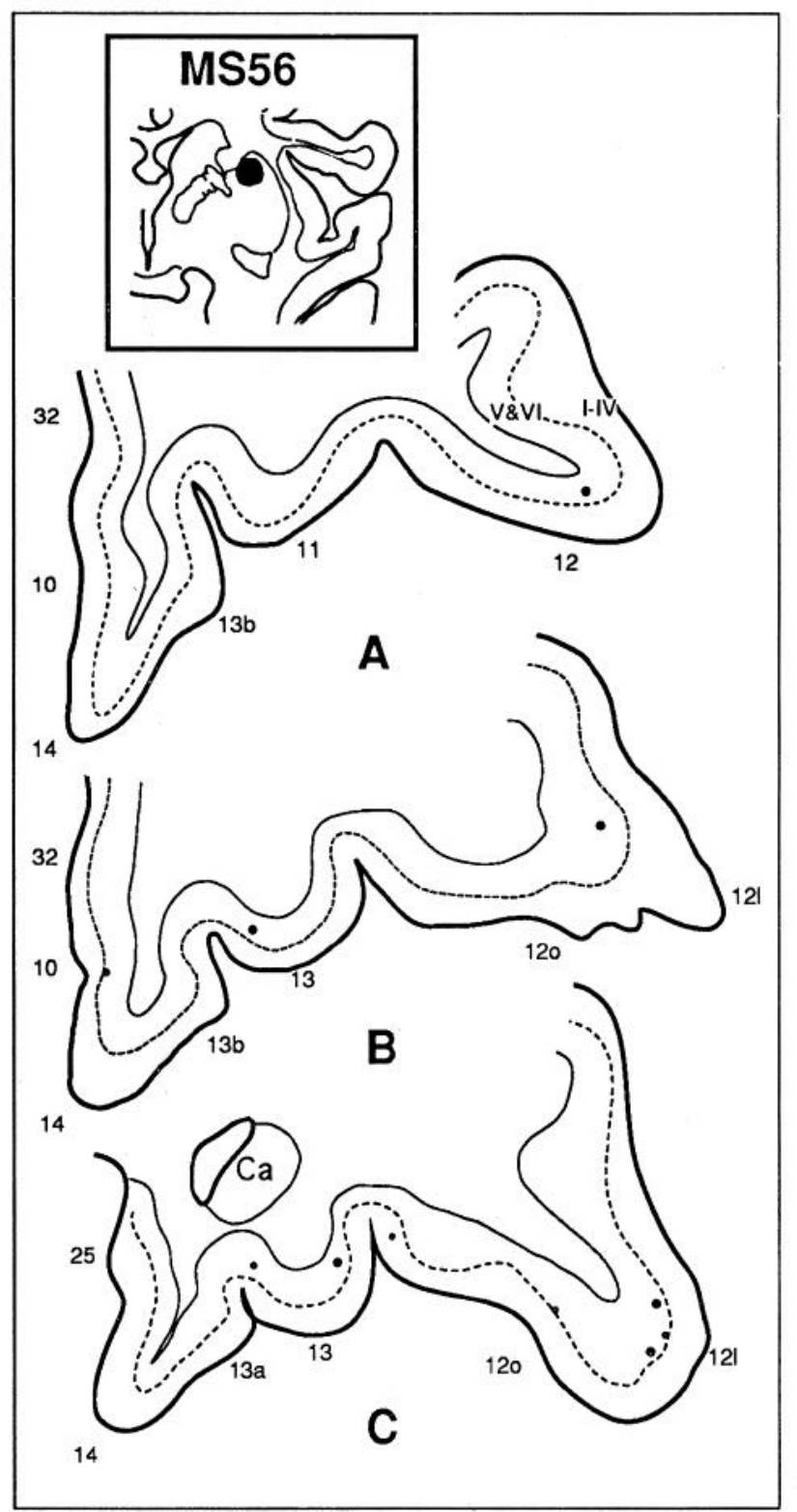

Figure 10. Distribution of retrogradely labeled neurons in the OMPFC following an injection into the dorsolateral striatum, case MS56: solid circle, group of three densely labeled cells; open circle, group of three lightly labeled cells. $\mathrm{Ca}$, caudate nucleus.

$0.3 \%$ Triton X-100 (PBS-T). Sections were preincubated in $10 \%$ normal goat serum (NGS) diluted with PBS-T for $30 \mathrm{~min}$. Tissue was then placed in the primary antisera, anti-LY 1:5000 (generously provided by Dr. H. Chang), or anti-HRP-WGA 1:2000 (Dako Corp., carpinteria, CA), or anti-PHA-L (1:500) in NGS-PBS-T for 4-5 nights at $4^{\circ} \mathrm{C}$. The avidin biotin reaction (rabbit Vectastain $\mathrm{ABC}$ kit, Vector Labs) was used to visualize the tracers. Staining was produced by incubating the tissue for $10-12 \mathrm{~min}$ in $3,3^{\prime}$ diaminobenzidine tetrahydrochloride and $0.01 \%$ hydrogen peroxide and intensified with $1 \%$ cobalt chloride and $1 \%$ nickel ammonium sulfate to yield a black reaction product. Sections were rinsed, dehydrated, and coverslipped with Permount (Fisher).

Each anterograde tracer, when placed in a similar position results in a similar projection pattern. However, the tritiated amino acid and LY injections often reveal denser terminal and fiber labeling than the PHA-L. There is no difference between retrograde labeling patterns of HRP-WGA and LY. 


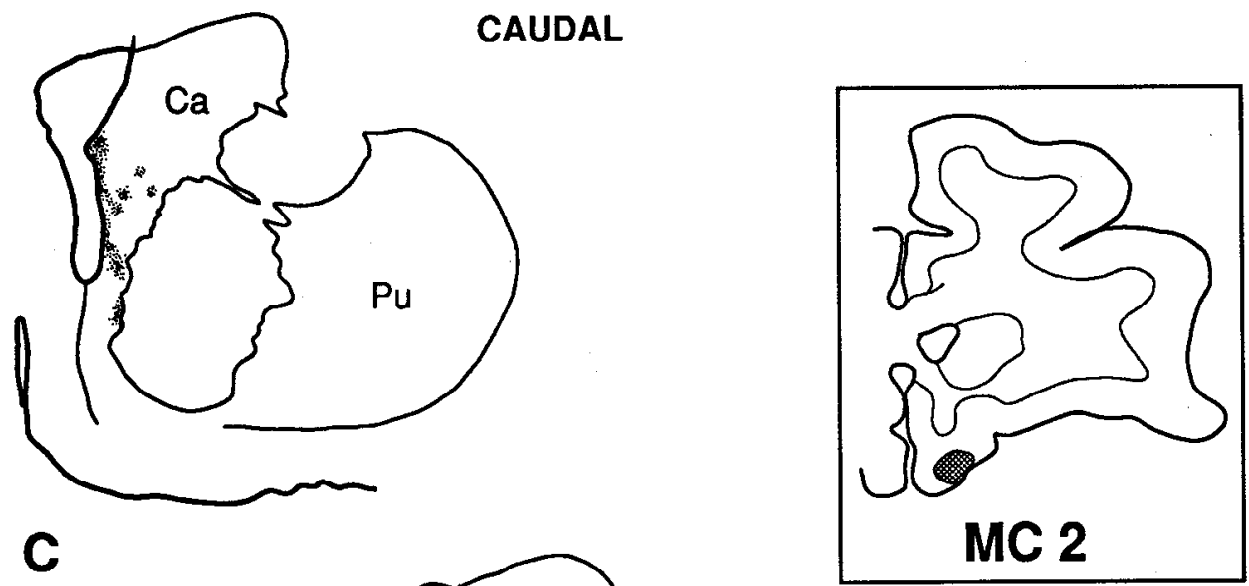

Figure 11. Distribution of anterogradely labeled terminals in the striatum following a tritiated amino acids injection into the orbitofrontal cortex, area 13b (Case MC2). Abbreviations: $\mathrm{Ca}$, caudate nucleus; $\mathrm{Pu}$, putamen; $N A$, nucleus accumbens.

Calbindin- $\mathrm{D}_{28 \mathrm{k}}$ (Cabp) immunoreactivity was used to define the boundaries of the shell region of the nucleus accumbens (Fig. $2 A$ ) as described previously (Friedman et al., 1992; Zahm and Brog, 1992; Meredith et al., 1993; Lynd-Balta and Haber, 1994c). Sections from each striatal case were double labeled for Cabp and the tracer to determine whether the placement of the injection site was within or outside of the shell region.

\section{Results}

OMPFC projections: retrograde studies

Injections of LY or WGA-HRP into the different striatal regions demonstrate that the medial ventral striatum receives the densest projection from the orbitofrontal cortex. This projection arises primarily from areas $13 \mathrm{a}, 13 \mathrm{~b}$, and 13 . The core of the nucleus accumbens also receives a dense projection but primarily from areas 11 and 13. After an injection into the lateral ventral striatum there are very few labeled cells in the orbitofrontal cortex. Very few labeled neurons are also observed in the orbitofrontal cortex following injections into the shell region of the ventral striatum. In general, the labeled cells in the orbitofrontal cortex after all injections are located primarily in layers V and VI. Areas 25 and 32 project to the medial ventral striatum and to the shell. The lateral striatum does not receive as dense a projection. All projections are bilateral, however far fewer contralateral cells are labeled than on the ipsilateral side.

The medial ventral striatum. Experiments MS14, MS43, and MS70 have injections placed into the medial part of the ventral striatum, but within the Cabp-positive area and therefore outside of the shell region of the nucleus accumbens as defined by Cabp-staining. Many labeled cells are found throughout the rostrocaudal extent of areas 25, 32, 13a, and 13b. Although they are primarily found in layers V and VI (Figs. 4, 5), several labeled cells are also observed in layers II, III, and superficial layer IV. In general, there are fewer labeled cells in 13 than in areas $13 a \&$ b. Scattered labeled cells are seen in layers $V$ and VI of areas 11 and 14 and parts of area 12 .

The shell region. Cases MS35 and MS71 are injections of HRP-WGA into the striatum that are confined to the Cabpnegative region in the ventral and most medial part of the ventral striatum, respectively. They are therefore considered to be within the shell region of the nucleus accumbens. There are 


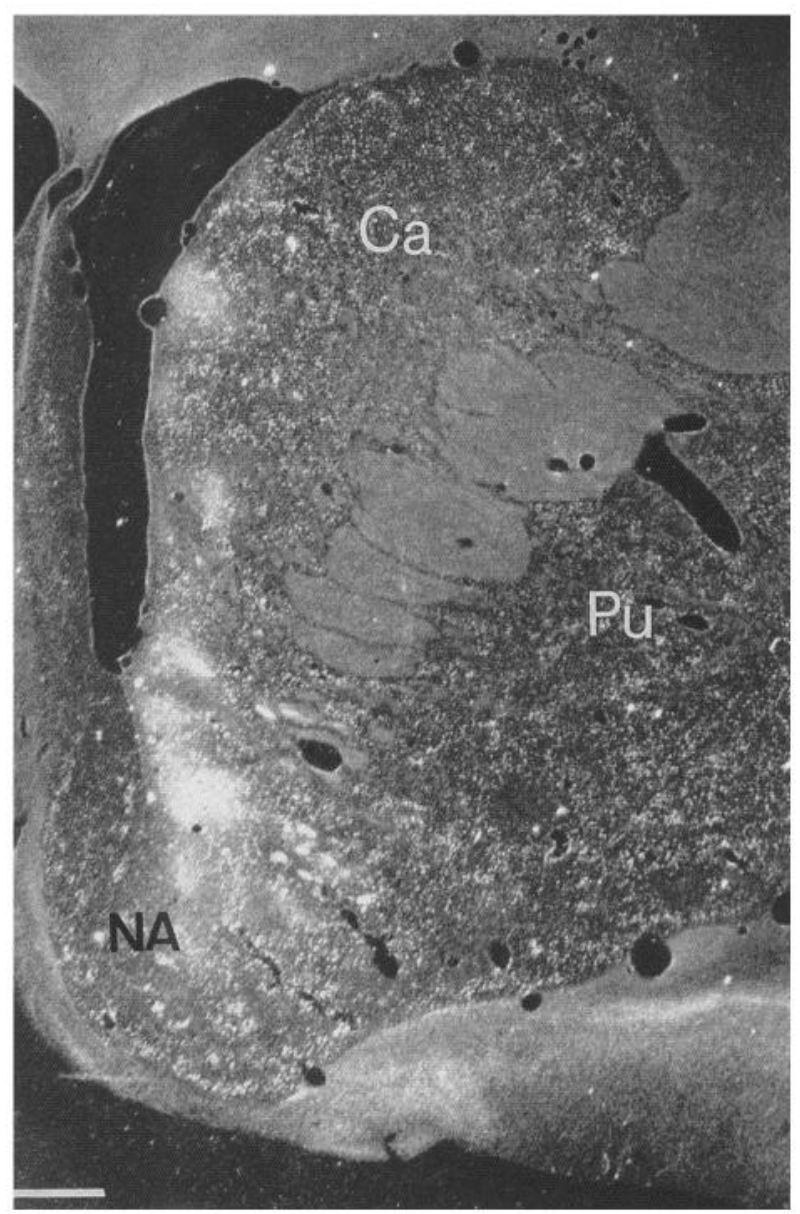

Figure 12. A dark-field photomicrograph of anterogradely transported label in the ventral striatum after an injection of tritiated amino acids into area 13b (Case MC2, corresponding to the level of $B$ ). Abbreviations: $C a$, caudate nucleus; $P u$, putamen; $N A$, nucleus accumbens. Scale bar, $1 \mathrm{~mm}$.

very few labeled cells in the orbitofrontal cortex after injections into the shell (Fig. 6). These cells are in layers V and VI and are lightly labeled. However, there are many labeled cells in the deep layers of areas 32 and 25.

The central ventral striatum. Case MS49 is an injection of LY into the central ventral striatum including the core of the nucleus accumbens. The injection site does not include the shell region of the nucleus accumbens, however it does include parts of the ventral caudate nucleus and ventral medial putamen. There are labeled neurons in area 11 and in area 13 (Fig. 7A, $B$ ). There are only a few labeled neurons in areas 14 and throughout most of area 12. Labeled cells are found primarily in layers V and VI, with a few labeled cells in layer III. Approximately half of the cells are intensely labeled while others are lightly stained. A few of the LY-positive cells in layer $\mathrm{V}$ exhibit a Golgi-like image, in which there are many well labeled dendrites. There are some cells labeled in areas 32 and 25; however, compared to the previously described cases they are relatively sparse and very lightly labeled.

The lateral ventral striatum. Experiment MS53 is an injection of LY into the lateral ventral striatum. There are not many labeled cells in the OMPFC following this injection. The cells that are labeled are evenly distributed in areas $13 \mathrm{a}, 13 \mathrm{~b}$, and
13 (Fig. 8). These cells are scattered throughout layers II-VI. In other areas such as 11,12 , or 14 , only a small number of labeled cells are observed, primarily in layer V. Most of the cells that are labeled show strong immunoreactivity, giving a Golgi-like image (Fig. 9).

The dorsolateral striatum. Case MS 56 is a relatively large injection of LY into the dorsolateral putamen. This striatal region receives inputs from the leg, arm, and head region of sensorimotor cortex (Künzle, 1975). Very few cells are found in the OMPFC (Fig. 10).

\section{OMPFC projections: anterograde studies}

Fiber labeling following all anterograde tracer injections into the orbitofrontal cortex produces a similar pattern in the medial region of the ventral striatum. Silver grains or LY-positive fibers are distributed in heterogeneous, patchy patterns that are circular or elliptical in shape, and surrounded by a fiber free area. The terminal regions are primarily confined to the medial part of the caudate nucleus and the dorsal part of the nucleus accumbens. There are few labeled fibers in the putamen. Within the nucleus accumbens, there are some terminals in the central part of the core of the nucleus accumbens. However, there are few labeled fibers in the medial and ventral part of the nucleus accumbens shell region. At caudal levels, the terminal fields are located within the ventromedial part of the body of the caudate nucleus and no fibers are found in the tail of the caudate nucleus. There is a similar pattern of labeling in the contralateral striatum, however the density of fibers is considerably less.

Area $13 a \& b$. Case MC2 is an injection of tritiated amino acids primarily into areas $13 \mathrm{a}$ and $13 \mathrm{~b}$. Patches of silver grains occupy the medial edge at the rostral pole of the striatum. At this rostral level, the fibers extend to the ventral base of the striatum (Fig. 11A). However, more caudally at the shell level of the nucleus accumbens, only scattered silver grains extend to the base of the striatum (Figs. $11 B, 12$ ). The dense patches of labeling occupy the medial edge of the caudate nucleus and the core of the nucleus accumbens. The silver grains are arranged in a series of several patches extending diagonally from the midline of the caudate nucleus, to the medial putamen, with few terminals in the shell region of the nucleus accumbens. There are terminals in the dorsal and central part of the nucleus accumbens. Caudally, the silver grain deposits are concentrated within the medial and ventral part of the body of the caudate nucleus.

Area 13. Case MC4 represents an injection site that is lateral to that of case MC2 and placed primarily into area 13. Rostrally, patches of silver grains extend ventrolaterally from the medial rim of the caudate nucleus (Fig. 13). There are dense patches of silver grains throughout the ventromedial caudate nucleus extending into the more dorsal parts of the rostral nucleus accumbens (Figs. 13, 14). Although, there are some patches of label in the shell of the nucleus accumbens, the main projection is outside of this region (Fig. 13B,C). The ventromedial caudate nucleus and the core of the nucleus accumbens receive the densest projection at this level. Little labeling is found in the putamen with the exception of its medial border with the nucleus accumbens. At the level of the anterior commissure and just caudal to it, the silver grain deposits occupy the ventral part of the caudate nucleus.

Area 14. Case MC19 is a LY injection into area 14 (Fig. 15). Rostrally, labeled fibers are concentrated in the ventro- 


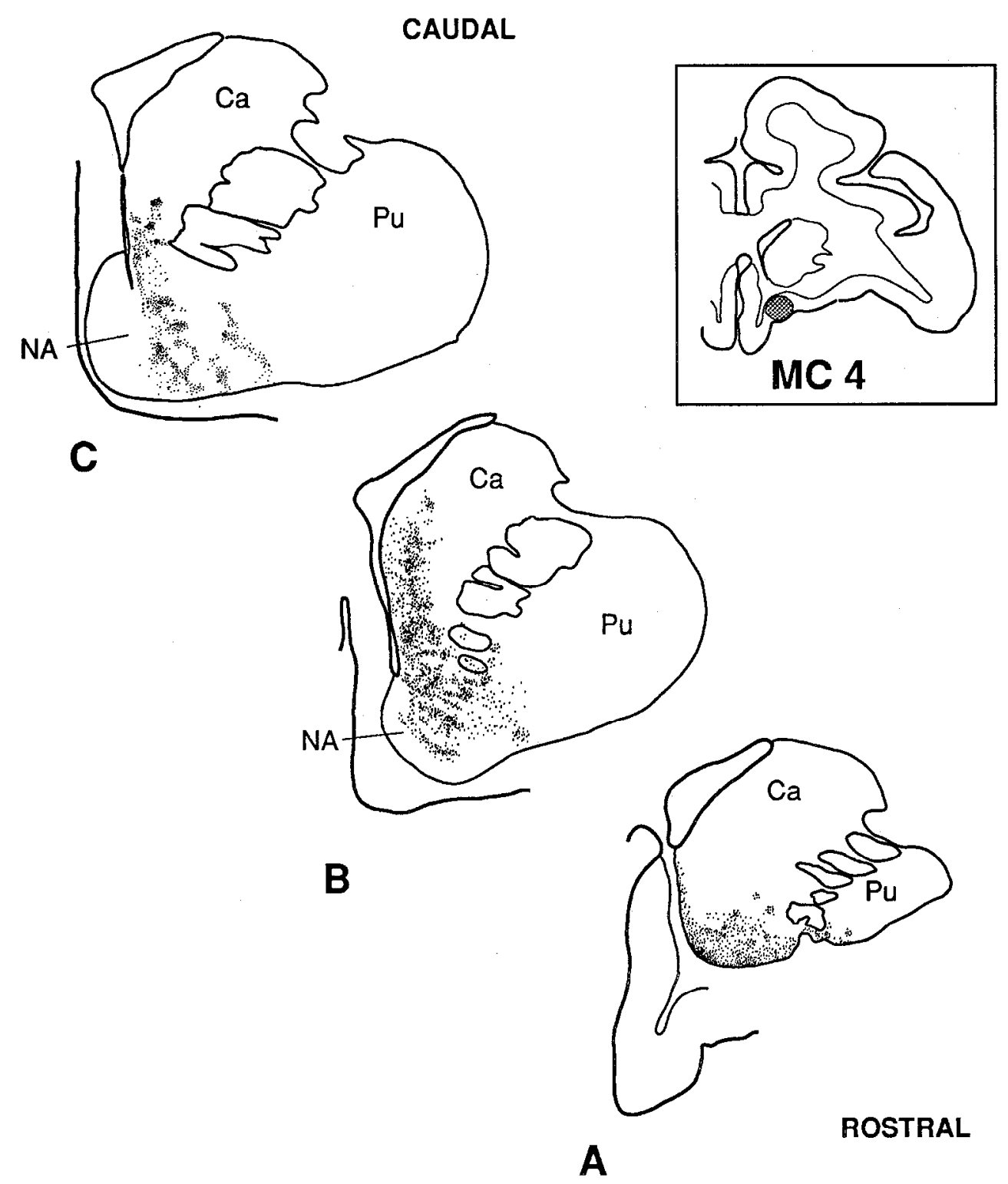

Figure 13. Distribution of anterogradely labeled terminals in the striatum following an injection of tritiated amino acids into the orbitofrontal cortex, area $13 \mathrm{~b}$ and 13 (Case MC4). Abbreviations: $C a$, caudate nucleus; $P u$, putamen; $N A$, nucleus accumbens.

medial part of the caudate nucleus. At the level of the nucleus accumbens, labeled fibers do not extend to the base of the striatum. As in the previous cases, although the projection is concentrated in the ventral striatum, the shell region receives only a sparse input.

\section{Striatal efferent connections}

Ventral striatal efferent projections have been previously described in detail (Haber et al., 1990). The LY and WGA-HRP reaction product in the globus pallidus and substantia nigra following the injections described here showed the same pattern of labeling as that in the more detailed study using PHA-L and tritiated amino acids as anterograde tracers. After all injections, there was a clear topographic organization of terminal labeling in the globus pallidus. Thus, in case MS 14, an injection into the medial ventral striatum within the Cabp-positive region, label is concentrated within the medial edge of the ventral pallidum, while an injection into the shell region labels terminals in the border region between the ventral pallidum and the bed nucleus of the stria terminalis. More lateral injections into the central and lateral ventral striatum label central and lateral regions of the ventral pallidum, respectively. In contrast, LY or WGA-HRP reaction product in the substantia nigra is found to extend over much of the medial-lateral extent of the dorsal substantia nigra, in the region of the pars compacta neurons. This pattern of labeling is similar regardless of the injection site placement in the different regions of the ventral striatum.

\section{Discussion}

The main projection from the OMPFC is to the medial and central ventral striatum but not to the lateral ventral striatum. OMPFC terminals lie close to the medial edge of the caudate nucleus and extend to the base of the rostral striatum. At the level of the nucleus accumbens, the projection from the orbitofrontal cortex is relatively sparse in the Cahp-free region. Terminals do not extend into central or dorsolateral striatal regions. The orbitofrontostriatal projection extends throughout the head and body of the caudate nucleus which has been shown previously (Selemon and Goldman-Rakic, 1985). There is a topography in that areas 32 and 25 project to the shell and medial ventral striatum while cells from areas $13 \mathrm{a}$ and $13 \mathrm{~b}$ 


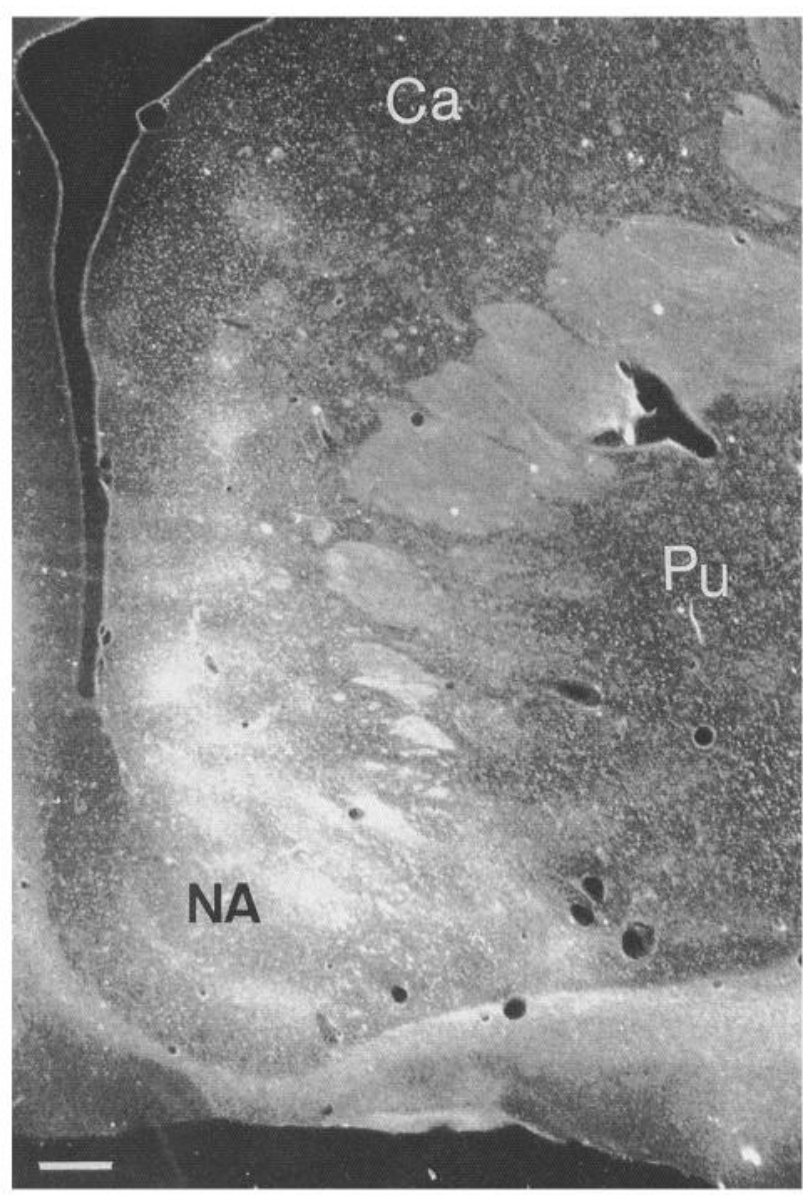

Figure 14. Photomicrograph taken from case MC4, at level $\mathrm{C}$ in Figure 14. Abbreviations: $\mathrm{Ca}$, caudate nucleus; $\mathrm{Pu}$, putamen; $\mathrm{NA}$, nucleus accumbens. Scale bar, $1 \mathrm{~mm}$.

project to the medial ventral striatum, and cells in area 13 project centrally (see Fig. 16). The projection from the OMPFC to the lateral ventral striatum is very small.

\section{Relationship between the OMPFC-striatal projection and the core/shell compartmentation}

The nucleus accumbens is considered to serve as an interface between the limbic and the extrapyramidal motor system (Nauta and Domesick, 1978; Mogenson et al., 1980, 1993). In monkeys, its medial and ventral boundaries are easily established. There is a ventral medial region that is Cabp-negative which we have defined as the shell. However, there is no clear immunohistochemical or cytoarchitectonic distinction dorsolaterally between the nucleus accumbens and adjacent parts of the striatum. The orbitofrontal projection in monkeys primarily terminates outside of the Cabp-negative shell region. Although some patches of fibers are found extending into this region, they are not extensive or very dense. Similarly, the number of neurons in the orbitofrontal cortex labeled after injections of retrograde tracers into the shell region are relatively few. The orbitofrontal cortex is continuous with the medial part of the prefrontal cortex, mainly areas 25 and 32 . The shell region receives a dense innervation from both areas 32 and 25 . In contrast, the medial ventral striatum receives a dense innervation from both the orbitofrontal cor- tex, in particular areas $13 \mathrm{a}$ and $13 \mathrm{~b}$ and from areas 25 and 32. The Cabp-negative shell region therefore has a more restricted innervation from the OMPFC cortex than the rest of the ventral striatum.

There is growing evidence in the rat that the shell is a unique part of the striatum (Alheid and Heimer, 1988; Zahm, 1989; Zahm and Heimer, 1990, 1993; Heimer et al., 1991a,b; Berendse et al., 1992a,b; Brog et al., 1993; Groenewegen and Berendse, 1994). These studies suggest a relatively close relationship between certain thalamic and cortical regions and the shell of the nucleus accumbens. The outputs from the shell to the pallidum and the substantia nigra indicate that segregation of this system continues in the output structures. In general, the primate studies reported here and elsewhere support the idea that certain midbrain, thalamic, and cortical regions are associated with the shell of the ventral striatum (Giménez-Amaya et al., 1995; Kunishio and Haber, 1994; Lynd-Balta and Haber, 1994c). However, these inputs are not restricted to the shell. Projections from the cingulate cortex to the shell arise most prominently from area 25 while the densest projections to the medial ventral striatum originate from more widespread areas including areas $25,24 \mathrm{a}, 24 \mathrm{~b}$, and 23a (Kunishio and Haber, 1994). The midline thalamic nuclei project most densely to the medial ventral striatum and to the shell region (Giménez-Amaya et al., 1995). In addition, however, the medial ventral striatum also receives a dense innervation from several thalamic nuclei (i.e., the ventral anterior nucleus) that do not project to the shell. Finally, the shell receives input from the dorsal tier of the midbrain dopaminergic neurons but not from the ventral tier (Lynd-Balta and Haber, 1994c). In contrast, both the dorsal and ventral tier neurons project to the rest of the ventral striatum. These studies illustrate that although the inputs to the shell region in primates are more restricted than to other parts of the ventral striatum, they are not unique. Figure 1 illustrates the more restricted inputs to the shell region that blend with additional inputs in the medial ventral striatum. Thus, in monkeys we can define a relatively small shell region which receives a specific and limited afferent projection. However, extending beyond the Cabp-negative borders is a more extensive area that receives inputs from both these limbic areas and from association areas.

\section{Cortical processing through the basal ganglia}

The orbitofrontal cortex projects primarily to the medial and central ventral striatum. Area 13 projects most densely to the central ventral striatum and areas $13 \mathrm{a}, 13 \mathrm{~b}$, and 14 project to the medial ventral striatum. This lateral to medial arrangement is continued in the projection of areas 25 and 32 to the shell and medial ventral striatum (Fig. 16). Areas 25 and 32 are closely linked to connections with the amygdala and the hippocampus (Amaral and Price, 1984; Amaral et al., 1992). Areas $13 \mathrm{a}$ and $13 \mathrm{~b}$ are in a pivotal position. Like areas 25 and 32 , they receive input from the amygdala and hippocampus, however it is not as dense an input. Furthermore it is adjacent to the multimodel sensory and premotor region of area 13 (S. T. Carmichael and J. L. Price, unpublished observations). Area 13 on the other hand receives little input from the amygdala and hippocampus. Thus these prefrontal cortical areas are arranged such that area $13 \mathrm{a}$ and $13 \mathrm{~b}$ provide a bridge between amygdala and association areas. The OMPFC input to the shell region is derived primarily from areas 32 and 25 . The medial ventral 


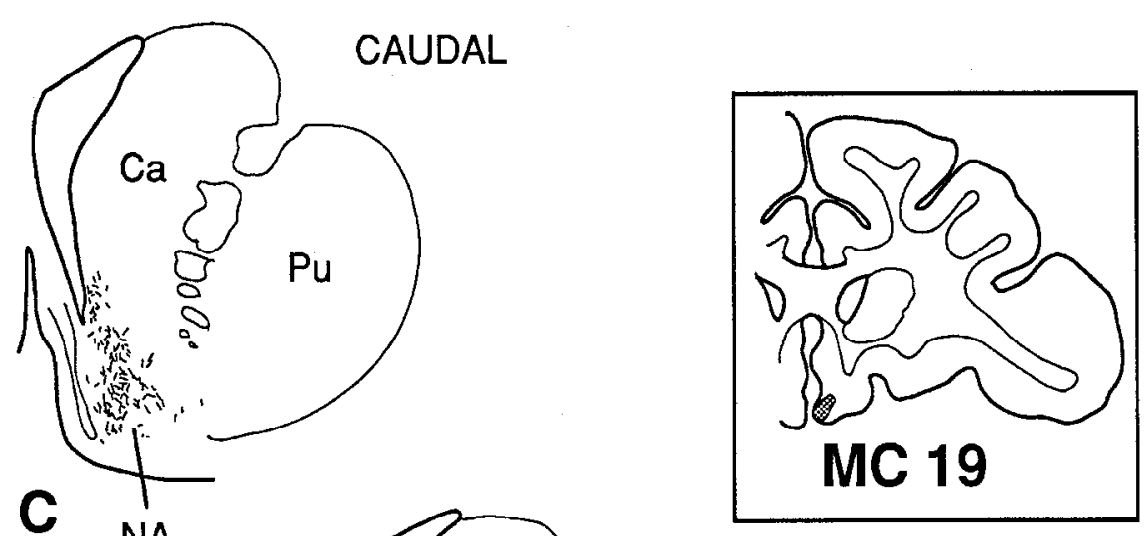

Figure 15. Distribution of anterogradely labeled fibers in the striatum following a LY injection into the OMPFC, area 14 (case MC19). Abbreviations: $\mathrm{Ca}$, caudate nucleus; $\mathrm{Pu}$, putamen; $N A$, nucleus accumbens. striatum receives input from these regions and from transition areas, $13 \mathrm{a}$ and $13 \mathrm{~b}$. In contrast, the central ventral striatum region receives input primarily from the multimodel OMPFC regions.

This topography of projections from the OMPFC to the ventral striatum is also reflected in the projections from the ventral striatum to the globus pallidus. The pattern of labeling in the globus pallidus and substantia nigra supports previous studies demonstrating that the medial and central ventral striatum project respectively to medial and central parts of the ventral pallidum (Haber et al., 1990). The shell region projects to the border area between the ventral pallidum and the bed nucleus of the stria terminalis (Fig. 17). The relationship between different regions of OMPFC projections through the striatum to the ventral pallidum can be best appreciated by comparing Figures 16 and 17. Areas 14, 13a, 13b, and 13 are represented primarily in the medial part of the ventral pallidum. Areas 25 and 32 are also represented here. In addition, areas 25 and 32 are represented medial to the ventral pallidum, in the border area with the subcommissural bed nucleus of the stria terminalis and in the lateral hypothalamus. Areas 11,13 , and 12 are primarily represented in the central part of the ventral pallidum. There is little representation of the OMPFC in the lateral ventral pallidum. Thus, the OMPFC areas are represented topographically in the medial and central globus pallidus.

Ventral striatal projections to the substantia nigra in monkeys are not as topographically arranged (Haber et al., 1990; LyndBalta and Haber, 1994a). All parts of the ventral striatum, including the shell region, terminate in the medial part of the pars reticulata at rostral levels and extend laterally, over a wide region of the substantia nigra pars compacta more caudally. Therefore, the relationship between different regions of the OMPRC through the ventral striatum to the midbrain is different than that to the ventral pallidum. Although areas 25 and 32 have a more dorsal representation than areas $13 \mathrm{a}, 13 \mathrm{~b}, 13,14$, and 12 , many of the terminal fields overlap extensively both in the rostromedial pars reticulata and in the pars compacta (Fig. 18). As a result, the OMPFC is represented throughout the same large area of the substantia nigra. Furthermore, other limbic-related regions are likely to be represented in the same region as indicated by the projection pattern from the lateral ventral striatum.

The output of the OMPFC through the basal ganglia therefore follows two patterns. In one, the separation of cortical inputs to the striatum is maintained through the globus pallidus. In the second pattern there is extensive overlap of ventral striatal terminals which extend over a relatively large re- 

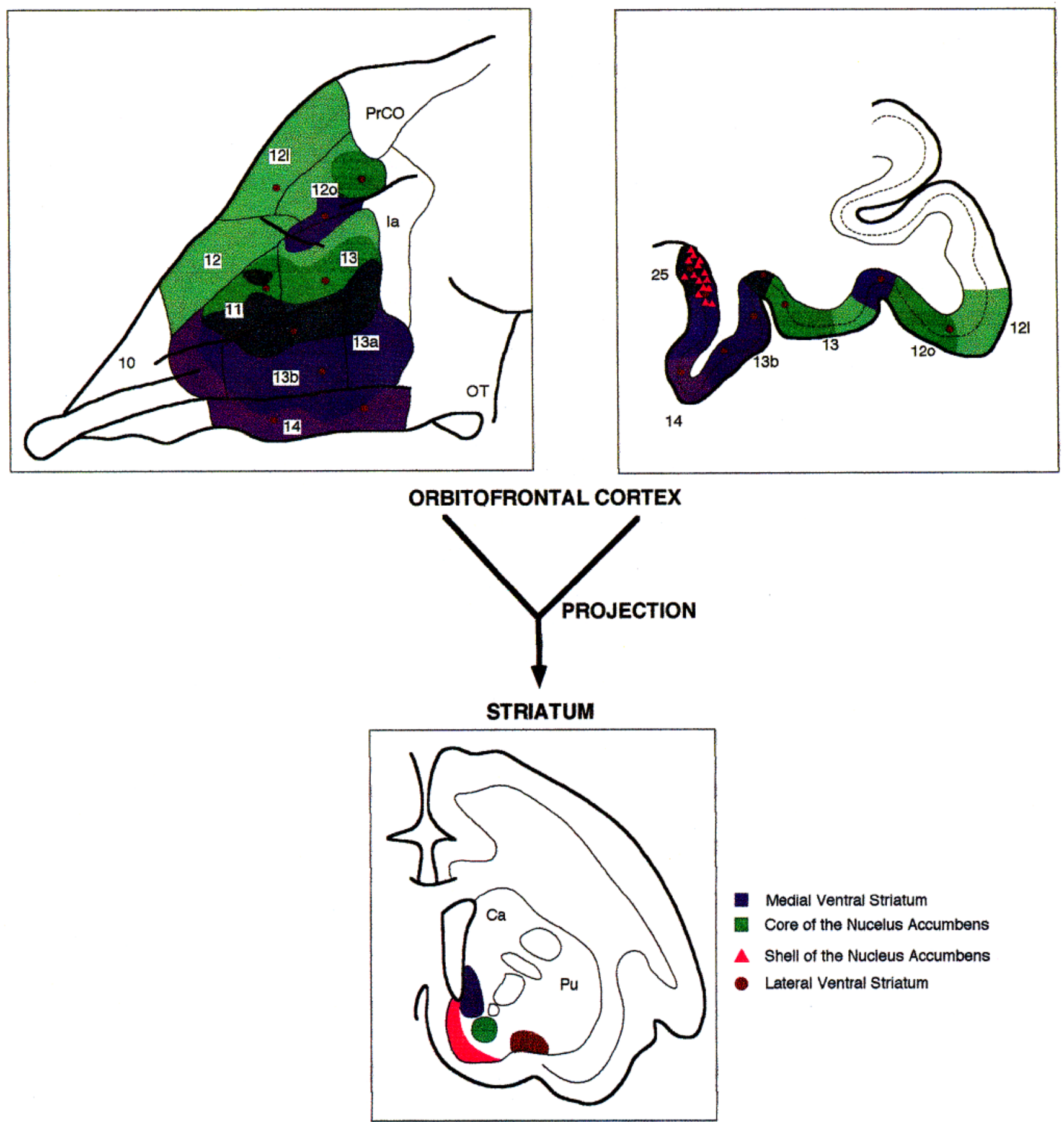

Medial Ventral Striatum

Core of the Nucelus Accumbens

A Shell of the Nucleus Accumbens

- Lateral Ventral Striatum

Figure 16. Schematic illustration of the topography of OMPFC projections to the striatum. The darker shades of color indicate higher density of labeled cells. Abbreviations: Ia, agranular insula cortex; OT, olfactory tubercle; $\mathrm{PrCo}$, precentral opercular cortex; $\mathrm{Ca}$, caudate nucleus; Pu, putamen.

gion of the substantia nigra. Therefore, the different OMPFC regions are likely to influence the same set of output dopaminergic neurons. This widespread influence on the substantia nigra, via the striatum, and subsequent nigrostriatal projections, places the substantia nigra in a key position for funneling information from the limbic system to affect a wider region of the striatum.

Furthermore, in primates, the midbrain dopaminergic input to frontal cortex is not limited to the prefrontal cortex. There is extensive innervation of the sensorimotor cortex as well (Gaspar et al., 1989, 1992). Emphasis on limbic/motor interactions in rats has been placed on the well-documented pathway from the ventral pallidum, through the medial dorsal (MD) nucleus of the thalamus to the prefrontal cortex (Conrad and Pfaff, 1976; Nauta and Domesick, 1978; Kelley and Domesick, 1982; Mogenson and Nielsen, 1983; Swerdlow and Koob, 1984; Haber et al., 


\section{STRIATUM}

\section{PROJECTION}

\section{VENTRAL PALLIDUM}
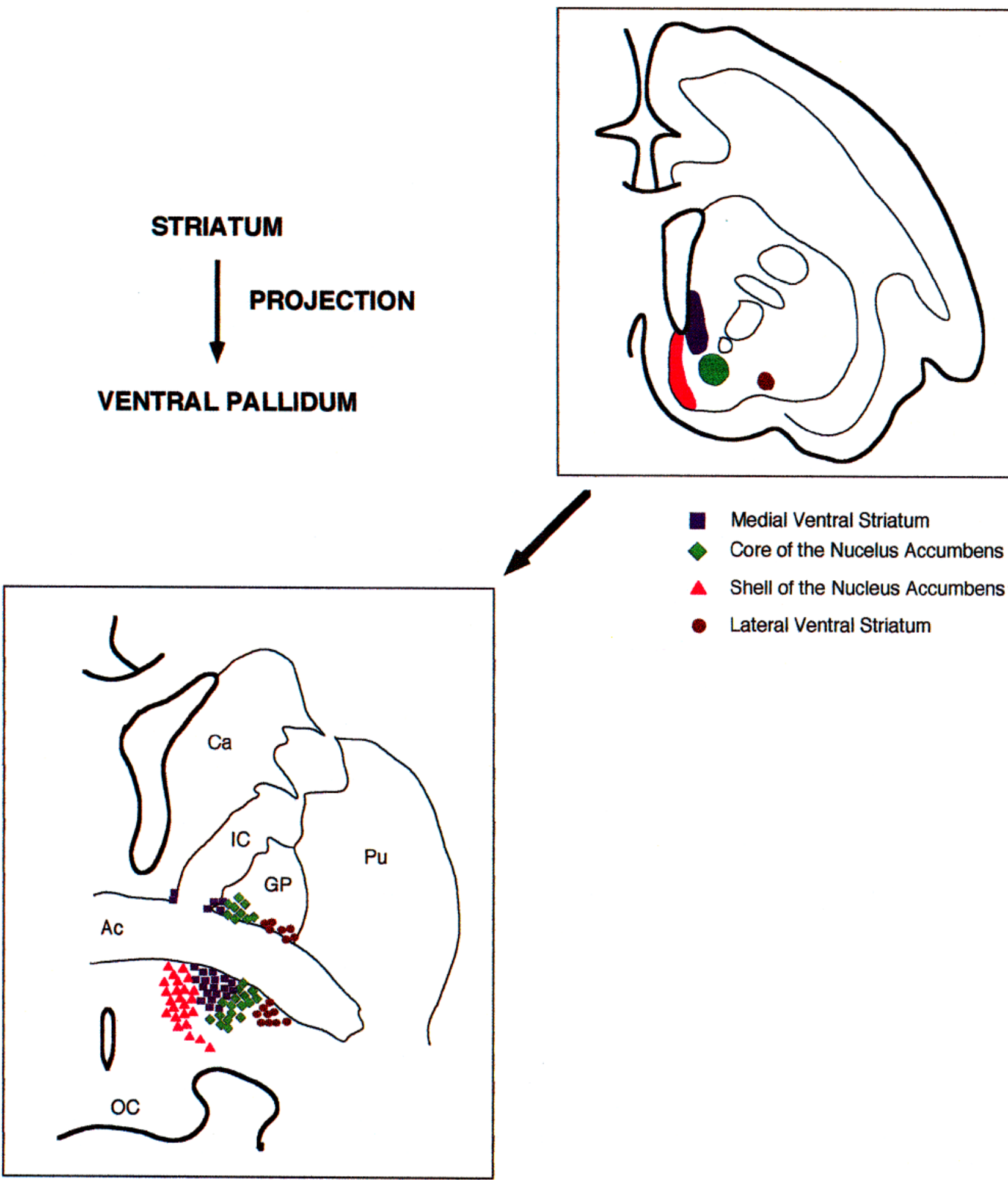

Medial Ventral Striatum

- Core of the Nucelus Accumbens

- Shell of the Nucleus Accumbens

- Lateral Ventral Striatum

Figure 17. Schematic illustration of the topography of projections from the ventral striatum to the ventral pallidum. Abbreviations: GP, globus pallidum; $A c$, anterior commissure; $V P$, ventral pallidum; $I C$, internal capsule.

Figure 18. Schematic illustration of the lack of topography of projections from the ventral striatum to the substantia nigra. Abbreviations: $S N$, substantia nigra; $R$, red nucleus. 

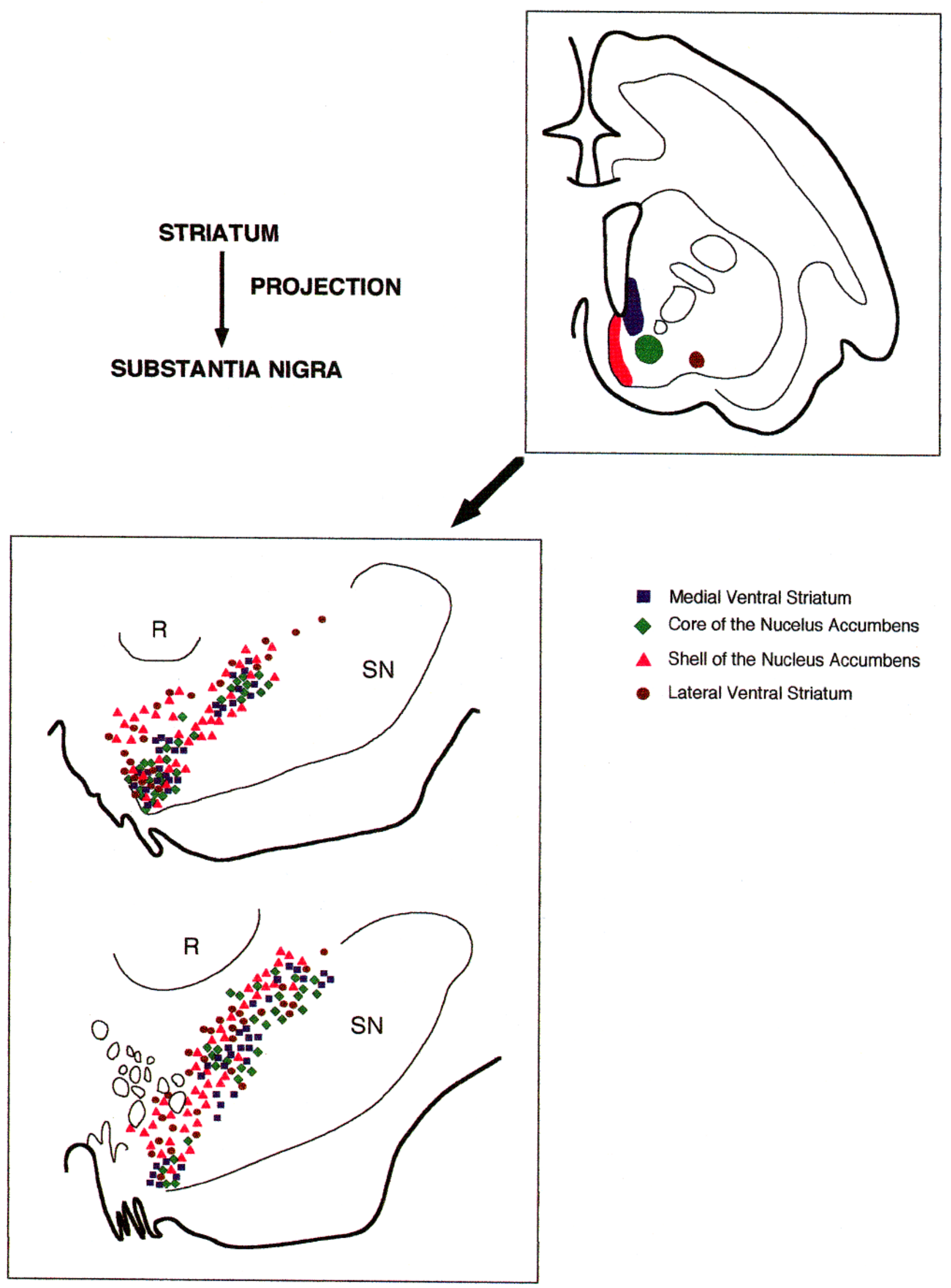
1985; Austin and Kalivas, 1991; Henriksen and Giachino, 1993; Mogenson et al., 1993). However, the prominence of a ventral pallidal/MD pathway in monkeys is questionable (Haber et al., 1993). One important route in which the limbic circuit can influence motor outcome is through the ventral striatal output to the dopaminergic cells of the substantia nigra which project to both the striatum and the frontal cortex.

\section{References}

Alexander GE, Crutcher MD, DeLong MR (1990) Basal ganglia-thalamocortical circuits: Parallel substrates for motor, oculomotor, "prefrontal" and "limbic" functions. Prog Brain Res 85:119.

Alheid GF, Heimer L (1988) New perspectives in basal forebrain organization of special relevance for neuropsychiatric disorders: the striatopallidal, amygdaloid, and corticopetal components of substantia innominata. Neuroscience 27:1-39.

Amaral DG, Price JL (1984) Amygdalo-cortical projections in the monkey (Macaca fascicularis). J Comp Neurol 230:465-496.

Amaral DG, Price JL, Pitkanen A, Charmichael ST (1992) Anatomical organization of the primate amygdaloid complex. In: The amygdala: neurobiological aspects of emotion, memory, and mental dysfunction, pp 1-66. New York: Wiley-Liss.

Apicella P, Ljungberg T, Scarnati E, Schultz W (1991) Responses to reward in Inonkey dorsal and ventral striatum. Exp Brain Res 85: 491-500.

Austin MC, Kalivas PW (1991) Dopaminergic involvement in locomotion elicited from the ventral pallidaum/substantia innominata. Brain Res 542:123-131

Barbas H, Pandya DN (1989) Architecture and intrinsic connections of the prefrontal cortex in the Rhesus monkey. J Comp Neurol 286: 353-375.

Berendse HW, Galisde Graaf Y, Groenewegen HJ (1992a) Topographical organization and relationship with ventral striatal compartments of prefrontal corticostriatal projections in the rat. J Comp Neurol 316:314-347

Berendse HW, Groenewegen HJ, Lohman AHM (1992b) Compartmental distribution of ventral striatal neurons projecting to the mesencephalon in the rat. J Neurosei 12:2079-2103.

Brog JS, Salyapongse A, Deutch AY, Zahm DS (1993) The patterns of afferent innervation of the core and shell in the "accumbens" part of the rat ventral striatum: immunohistochemical detection of retrogradely transported fluoro-gold. J Comp Neurol 338:255-278.

Carmichael ST, Price II. (1994) Architectonic subdivision of the orbital and medial prefrontal cortex in the macaque monkey. J Comp Neurol, in press.

Conrad LCA, Pfaff DW (1976) Autoradiographic tracing of nucleus accumbens efferents in the rat. Brain Res 113:589-596.

Flaherty AW, Graybiel AM (1994) Input-output organization of the sensorimotor striatum in the squirrel monkey. J Neurosci 14:599610.

Friedman DP, Porrino LJ, Vinsant S (1992) Anatomical analysis of the ventral striatum in the macaque monkey. Soc Neurosci Abstr 18:307.

Gaspar P, Berger B, Febvret A, Vigny A, Henry JP (1989) Catecholamine innervation of the human cerebral cortex as revealed by comparative immunohistochemistry of tyrosine hydroxylase and dopamine-beta-hydroxylase. J Comp Neurol 279:249-271.

Gaspar P, Stepneiwska I, Kaas JH (1992) Topography and collateralization of the dopaminergic projections to motor and lateral prefrontal cortex in owl monkeys. J Comp Neurol 325:1-21.

Giménez-Amaya JM, McFarland NR, de las Heras S, Haber SN (1995) The organization of thalamic projections to the ventral striatum in the primate. J Comp Neurol 354:127-149.

Groenewegen HJ, Berendse HW (1994) Anatomical relationships between the prefrontal cortex and the basal ganglia in the rat. In: Motor and cognitive functions of the prefrontal cortex (Thierry A-M, et al., eds), pp 51-77. Berlin: Springer.

Haber SN, Groenewegen HJ, Grove EA, Nauta WJH (1985) Efferent connections of the ventral pallidum. Evidence of a dual striatopallidofugal pathway. J Comp Neurol 235:322-335.

Haber SN, Lynd E, Klein C, Groenewegen HJ (1990) Topographic organization of the ventral striatal efferent projections in the rhesus monkey: an anterograde tracing study. J Comp Neurol 293:282298.

Haber SN, Lynd-Balta E, Spooren WPTM (1992) Integrative aspects of basal ganglia circuitry. In: Basal ganglia IV (Percheron G, McKenzie JS, eds).

Haber SN, Lynd-Balta E, Mitchell SJ (1993) The organization of the descending ventral pallidal projections in the monkey. J Comp Neurol 329:111-129.

Heimer L, de Olmos J, Alheid GF, Zaborszky L (1991a) "Perestroika" in the basal forebrain: opening the border between neurology and psychiatry. In: Progress in brain research, Vol 87 (Holstege G, ed), pp 109-165. New York: Elsevier.

Heimer L, Zahm DS, Churchill L, Kalivas PW, Wohltmann C (1991b) Specify in the projection patterns of accumbal core and shell in the rat. Neuroscience 41:89-125.

Henriksen SJ, Giachino J (1993) Functional characterists of nucleus accumbens neurons: evidence obtained from in vivo electrophysiological recordings. In: Neuropsychiatry (Kalivas PW, Barnes CD, eds), pp 101-124. Boca Raton: CRC.

Jones EG, Leavitt RY (1974) Retrograde axonal transport and the demonstration of non-specific projections to the cerebral cortex and striatum from thalamic intralaminar nuclei in the rat, cat and monkey. J Comp Neurol 154:349-378.

Kelley AE, Domesick VB (1982) The distribution of the projection from the hippocampal formation to the nucleus accumbens in the rat: an anterograde and retrograde-horseradish peroxidase study. Neuroscience 7:2321-2336.

Kemel ML, Desban M, Glowinski J, Gauchy C (1992) Functional heterogeneity of the matrix compartment in the cat caudate nucleus as demonstrated by the cholinergic presynaptic regulation of dopamine release. Neuroscience 50:597-610.

Koob GF, Robledo P, Markou A, Caine SB (1994) The mesocorticolimbic circuit in drug dependence and reward-a role for the extended amygdala? In: Limbic motor circuits and neuropsychiatry (Kalivas PW, Barnes CD, eds). Boca Raton: CRC.

Kunishio K, Haber SN (1994) The primate cingulostriatal projection: limbic striatal versus sensorimotor striatal input. J Comp Neurol 350:337-356.

Lynd-Balta E, Haber SN (1994a) Primate striatonigral projections: a comparison of the sensorimotor-related striatum and the ventral striatum. J Comp Neurol 343:1-17.

Lynd-Balta E, Haber SN (1994b) The organization of midbrain projections to the striatum in the primate: sensorimotor-related striatum versus ventral striatum. Neuroscience 59:625-640.

Lynd-Balta E, Haber SN (1994c) The organization of midbrain projections to the ventral striatum in the primate. Neuroscience 59: $609-623$.

Meredith GE, Pattiselanno A, Groenewegen HJ, Haber SN (1993) Shell and core in the primate ventral striatum identified with antibodies against calbindin. Soc Neurosci Abstr.

Mogenson GJ, Nielsen MA (1983) Evidence that an accumbens to subpallidal GAGAergic projection contributes to locomotor activity. Brain Res Bull 11:309-314.

Mogenson GJ, Jones DL, Yim CY (1980) From motivation to action: functional interface between the limbic system and the motor system. Prog Neurobiol 14:69-97.

Mogenson GJ, Brudzynski SM, Wu M, Yang CR, Yim CCY (1993) From motivation to action: a review of dopaminergic regulation of limbic-nucleus accumbens-pedunculopontine nucleus circuitries involved in limbic-motor integration. In: Limbic motor circuits and neuropsychiatry (Kalivas PW, Barnes CD, eds), pp 193-236. Boca Raton: CRC.

Napier I'C, Mitrovic I, Churchill LC, Klitenick MA, Kalivas PW (1993) Substance $P$ in the projection from the nucleus accumbens to ventral pallidum: anatomy, electrophysiology and behavior. $\mathrm{J}$ Neurosci.

Nauta WJH, Domesick VB (1978) Crossroads of limbic and striatal circuitry: hypothalamic-nigral connections. In: I imbic mechanisms (Livingston KE, Hornykiewicz O, eds), pp 75-93. New York: Plenum.

Nauta WJH, Smith GP, Faull RLM, Domesick VB (1978) Efferent connections and nigral afferents of the nucleus accumbens septi in the rat. Neuroscience 3:385-401.

Percheron G, Yelnik J, Francois C (1984) The primate striato-pallidunigral system: an integrative system for cortical information. In: 
The basal ganglia: structure and function (McKenzie JS, Kemm RE, Wilcock LN, eds). London: Plenum.

Poletti CE, Cresswell G (1977) Fornix system efferent projections in the squirrel monkey: an experimental degeneration study. J Comp Neurol 175:101-128.

Ray JP, Price JL (1993) The organization of projections from the mediodorsal nucleus of the thalamus to orbital and medial prefrontal cortex in Macaque monkeys. J Comp Neurol 337:1-31.

Russchen FT, Bakst I, Amaral DG, Price JL (1985) The amygdalostriatal projections in the monkey. An anterograde tracing study. Brain Res 329:241-257.

Schultz W (1992) Activity of dopamine neurons in the behaving primate. Neurosciences 4:129-138.

Schultz W, Apicella P, Scarnati E, Ljungberg T (1992) Neuronal activity in monkey ventral striatum related to the expectation of reward. J Neurosci.

Schultz W, Apicella P, Ljungberg T (1993) Responses of monkey dopamine neurons to reward and conditioned stimuli during successive steps of learning a delayed response task. J Neurosci 13: 900-913.

Selemon LD, Goldman-Rakic PS (1985) Longitudinal topography and interdigitation of corticostriatal projections in the rhesus monkey: J Neurosci 5:776-794.
Somogyi P, Bolam JP, Totterdell S, Smith AD (1981) Monosynaptic input from the nucleus accumbens-ventral striatum region to retrogradely labelled nigrostriatal neurones. Brain Res 217:245-263.

Swerdlow NR, Koob GJ (1984) A neural substrates of apomorphinestimulated locomotor activity following denervation of the nucleus accumbens. Life Sci 35:2537-2544.

Walker AE (1940) A cytoarchitectural study of the prefronal area of the macaque monkey. J Comp Neurol 73:59-86.

Zaborszky L, Alheid GF, Beinfeld MC, Eiden LE, Heimer L, Palkovits M (1985) Cholecystokinin innervation of the ventral striatum: a morphological and radioimmunological study. Neuroscience 14: $427-453$.

Zahm DS (1989) The ventral striatopallidal parts of the basal ganglia in the rat. II. Compartmentation of ventral pallidal efferents. Neuroscience 30:33-50.

Zahm DS, Brog JS (1992) On the significance of subterritories in the "accumbens" part of the rat ventral striatum. Neuroscience 50:751767.

Zahm DS, Heimer L (1990) Two transpallidal pathways originating in the rat nucleus accumbens. J Comp Neurol 302:437-446.

Zahm DS, Heimer L (1993) Specificity in the efferent projections of the nucleus accumbens in the rat: comparison of the rostral pole projection patterns with those of the core and shell. J Comp Neurol $327: 220-232$. 